\title{
Optimal electromagnetic hybrid negative current compensation method for high-speed railway power supply system
}

\author{
Jiaxin YUAN $^{1}$, Yongheng ZHONG $^{1}$, Chenmeng ZHANG ${ }^{1}$, \\ Wenjun ZENG ${ }^{1}$, Baichao CHEN ${ }^{1}$, Cuihua TIAN ${ }^{1}$, Changhong DENG ${ }^{1}$, \\ Min ZHOU ${ }^{2}$, Kazuhiro MURAMATSU ${ }^{3}$, Jin WANG ${ }^{4}$
}

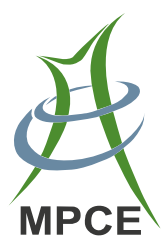

\begin{abstract}
To achieve economical compensation for the huge-capacity negative sequence currents generated by high-speed railway load, an electromagnetic hybrid compensation system (EHCS) and control strategy is proposed. The EHCS is made up of a small-capacity railway static power conditioner (RPC) and a large-capacity magnetic static var compensator (MSVC). Compared with traditional compensation methods, the EHCS makes full use of the SVC's advantages of economy and reliability and of RPC's advantages of technical capability and flexibility. Based on the idea of injecting a negative sequence, the compensation principle of the EHCS is analyzed in detail. Then the minimum installation capacity of an EHCS is theoretically deduced. Furthermore, a constraint optimization compensation strategy that meets national standards, which
\end{abstract}

CrossCheck date: 26 November 2015

Received: 13 October 2015 / Accepted: 14 December 2015 / Published online: 19 January 2016

(c) The Author(s) 2016. This article is published with open access at Springerlink.com

$\square$ Jiaxin YUAN
yjx98571@163.com
Yongheng ZHONG
zyhwhuer@126.com
Chenmeng ZHANG
916188925@qq.com
Wenjun ZENG
240308630@qq.com
Baichao CHEN
whgycbc@163.com
Cuihua TIAN
837047674@qq.com
Changhong DENG
dengch-whu@163.com

reduces compensation capacity further, is proposed. An experimental platform based on a digital signal processor (DSP) and a programmable logic controller (PLC) is built to verify the analysis. Simulated and experimental results are given to demonstrate the effectiveness and feasibility of the proposed method.

Keywords Unbalanced load, Electromagnetic hybrid compensation, Railway static power conditioner (RPC), Magnetic static var compensator (MSVC), Capacity optimize

\section{Introduction}

With its efficiency, fast speed, safety, energy-saving environmental protection and other advantages, high-speed railway obtained rapid development all over the world, especially in Asia and Europe [1].

Instead of the AC-DC thyristor-based technology, highspeed electric locomotives mainly adopt the AC-DC-AC

Min ZHOU

zhoumin@whu.edu.cn

Kazuhiro MURAMATSU

muramatu@cc.saga-u.ac.jp

Jin WANG

wang.1248@osu.edu

1 School of Electrical Engineering, Wuhan University, Wuhan, Hubei, China

2 School of Resource and Environment Science, Wuhan University, Wuhan, Hubei, China

3 Department of Advanced Technology Fusion, Saga University, Saga, Japan

4 Electrical and Computer Engineering, Ohio State University, Columbus, OH, USA 
pulse-width-modulated (PWM) technology transmission. Therefore, high-speed electric locomotive load has larger capacity, higher power factor and lower content of harmonic. However, the negative sequence and the transient impact are more serious, which may cause nearby the three-phase asynchronous motor operating conditions deteriorate such as generate heating, vibration, and relay protection misoperation $[2,3]$.

To solve the negative current issue, there are two basic ways: optimize traction power supply system and install unbalanced compensation device. The first method includes: changing phase in turn, increasing the voltage level access and using the balanced transformer [4]. These methods can reduce negative current, but increase the cost of transmission line and traction substation, which may not meet the relevant unbalance standards such as international standard IEC and national standard GB/T15543-2008 [5]. Installing compensation device is economical and easy for practical application without changing other devices. However, compensation method based on thyristor controlled reactor (TCR) type static var compensator (SVC) may bring more harmonic pollution to power supply system [6]. Magnetically controllable reactor (MCR) has the advantages of direct access to the high voltage system, high reliability and low cost. Multi-stage saturable type of magnetic-valve controllable reactor (MSMCR) can reduce harmonic current output further [7]. SVC compensating for unbalance and reactive power are highly reliable and with low cost, but with low harmonics generated and slow response speed.

The other compensation device is full-control power electronics device. Reference [8] analyzed the railway static power conditioner (RPC) application in the doubleloop control strategy of the $\mathrm{V} / \mathrm{V}$ transformer traction power system. Reference [9] carried on a detailed study of the RPC control method, and proposed a kind of active current, reactive current and harmonic current detection method. References [10-12] proposed and analyzed a novel HPQC with a proper parameter design for minimum DC operation voltage under comprehensive fundamental and harmonic compensation in co-phase power supply system. Since this system hasn't been widely applied, more analysis in V/V transformer traction power system is needed. References $[13,14]$ proposed and analyzed a novel RPC with asymmetric passive LC branches, which can operate with lower DC-link voltage. RPC has good dynamic response and low harmonics, which is fit for comprehensive solving highspeed railway negative sequence and harmonic problems. However, its wide application is restricted due to high installation and operational cost.
Based on the above analysis, the topology, principle, and control strategy of EHCS are proposed in this paper. The EHCS consists of a small capacity RPC, three sets of large capacity MSVC and high-pass filters. The contributions of this paper are the following: the minimum capacity of an EHCS is deduced in different compensation aims; cooperation control strategy.

\section{Negative sequence characteristic of high-speed railway load}

High-speed railway traction power system is mainly composed of traction substations and traction network distributed along the railway. Three-phase V/V transformer has been widely applied in China, which is of simple structure and high capacity utilization. The primary windings are respectively connected to $\mathrm{AC}$ and $\mathrm{BC}$ phase of the three-phase power system; the secondary winding terminals are respectively connected to contact line positive feeder and rail. V/V transformer is analyzed in this paper as an example.

$$
\left[\begin{array}{c}
\boldsymbol{I}_{A} \\
\boldsymbol{I}_{B} \\
\boldsymbol{I}_{C}
\end{array}\right]=\frac{1}{K}\left[\begin{array}{cc}
1 & 0 \\
0 & 1 \\
-1 & -1
\end{array}\right]\left[\begin{array}{c}
\boldsymbol{I}_{\alpha . l} \\
\boldsymbol{I}_{\beta .1}
\end{array}\right]
$$

where $\boldsymbol{I}_{\mathrm{A}}, \boldsymbol{I}_{\mathrm{B}}, \boldsymbol{I}_{\mathrm{C}}$ are three phase currents of the traction transformer primary side; $\boldsymbol{I}_{\alpha .1}, \boldsymbol{I}_{\beta .1}$ are load current of two power arm, $K$ is the ratio of traction transformer.

According to symmetrical component method, the positive and negative sequence current calculation formulas are expressed as follows:

$$
\begin{aligned}
{\left[\begin{array}{l}
\boldsymbol{I}^{+} \\
\boldsymbol{I}^{-}
\end{array}\right] } & =\frac{1}{3}\left[\begin{array}{ccc}
1 & \alpha & \alpha^{2} \\
1 & \alpha^{2} & \alpha
\end{array}\right]\left[\begin{array}{l}
\boldsymbol{I}_{\mathrm{A}} \\
\boldsymbol{I}_{\mathrm{B}} \\
\boldsymbol{I}_{\mathrm{C}}
\end{array}\right] \\
& =\frac{\sqrt{3}}{3 K}\left[\begin{array}{cc}
\frac{\sqrt{3}}{2}-j \frac{1}{2} & -j \\
\frac{\sqrt{3}}{2}+j \frac{1}{2} & j
\end{array}\right]\left[\begin{array}{l}
\boldsymbol{I}_{\alpha .1} \\
\boldsymbol{I}_{\beta .1}
\end{array}\right]
\end{aligned}
$$

where $\boldsymbol{I}^{+}$and $\boldsymbol{I}^{-}$are the positive and negative sequence current, $\alpha=-1 / 2+j \sqrt{3} / 2$.

In Fig. $1, \boldsymbol{U}_{\mathrm{A}}, \boldsymbol{U}_{\mathrm{B}}, \boldsymbol{U}_{\mathrm{C}}$ are three phase voltage of the traction transformer primary side; $\boldsymbol{U}_{\alpha}, \boldsymbol{U}_{\beta}$ the load voltage of two power supply arms; $\varphi_{\alpha}$ and $\varphi_{\beta}$ the impedance angles of $\alpha$-phase and $\beta$-phase. Take $\boldsymbol{U}_{\alpha}$ as a reference vector, then $\boldsymbol{I}_{\alpha .1}=I_{\alpha .1 \mathrm{~m}} \angle\left(-\varphi_{\alpha}\right), \boldsymbol{I}_{\beta .1}=I_{\beta .1 \mathrm{~m}} \angle\left(-60^{\circ}-\varphi_{\beta}\right)$, while $I_{\alpha .1 \mathrm{~m}}$ and $I_{\beta .1 m}$ are RMS of $\boldsymbol{I}_{\alpha .1}$ and $\boldsymbol{I}_{\beta .1}$, respectively. The new equation can be obtained as follows, substituting $\boldsymbol{I}_{\alpha .1}$ and $\boldsymbol{I}_{\beta .1}$ in (2) with $I_{\alpha .1 \mathrm{~m}} \angle\left(-\varphi_{\alpha}\right)$ and $I_{\beta .1 \mathrm{~m}} \angle\left(-60^{\circ}-\varphi_{\beta}\right)$ : 


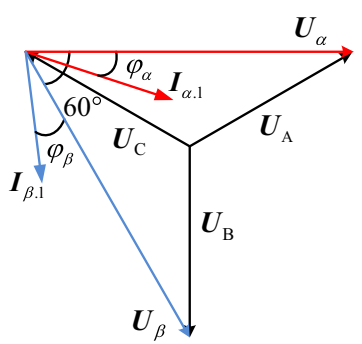

Fig. 1 Voltage and current vector diagram

$\boldsymbol{I}^{-}=\frac{\sqrt{3}}{3 K}\left[I_{\alpha \cdot \operatorname{lm}} \angle\left(-30^{\circ}-\varphi_{\alpha}\right)+I_{\beta \cdot \operatorname{lm}} \angle\left(-150^{\circ}-\varphi_{\beta}\right)\right]$

$\boldsymbol{I}^{+}=\frac{\sqrt{3}}{3 K}\left[I_{\alpha \cdot \operatorname{lm}} \angle\left(30^{\circ}-\varphi_{\alpha}\right)+I_{\beta \cdot \operatorname{lm}} \angle\left(30^{\circ}-\varphi_{\beta}\right)\right]$

Assuming the ratio of peak value of load current of two power supply arms is $m=\frac{I_{\beta \cdot 1 \mathrm{~m}}}{I_{\alpha \cdot \mathrm{lm}}}$, the current unbalanced degree $\varepsilon_{I}$ is deduced as follows:

$$
\begin{aligned}
\varepsilon_{I} & =\frac{\left|\boldsymbol{I}^{-}\right|}{\left|\boldsymbol{I}^{+}\right|} \\
& =\sqrt{1+\frac{2 m \cos \left(\varphi_{\alpha}-\varphi_{\beta}-120^{\circ}\right)-2 m \cos \left(\varphi_{\alpha}-\varphi_{\beta}\right)}{1+m^{2}+2 m \cos \left(\varphi_{\alpha}-\varphi_{\beta}\right)}}
\end{aligned}
$$

\section{Topology and principle of EHCS}

\subsection{Topology of EHCS}

Figure 2 shows the topology of the proposed EHCS. $\boldsymbol{I}_{\alpha}$, $\boldsymbol{I}_{\beta}$ are current of the traction transformer secondary side; $\boldsymbol{I}_{\alpha .1}, \boldsymbol{I}_{\beta .1}$ are load currents of two power supply arm; $\boldsymbol{I}_{\alpha}^{\prime}, \boldsymbol{I}_{\beta}^{\prime}$, $\boldsymbol{I}_{\gamma}^{\prime \prime}$ are three sets of MSVC output currents; and $\boldsymbol{I}_{\alpha}^{\prime \prime}, \boldsymbol{I}_{\beta}^{\prime \prime}$ are two inverter output currents.

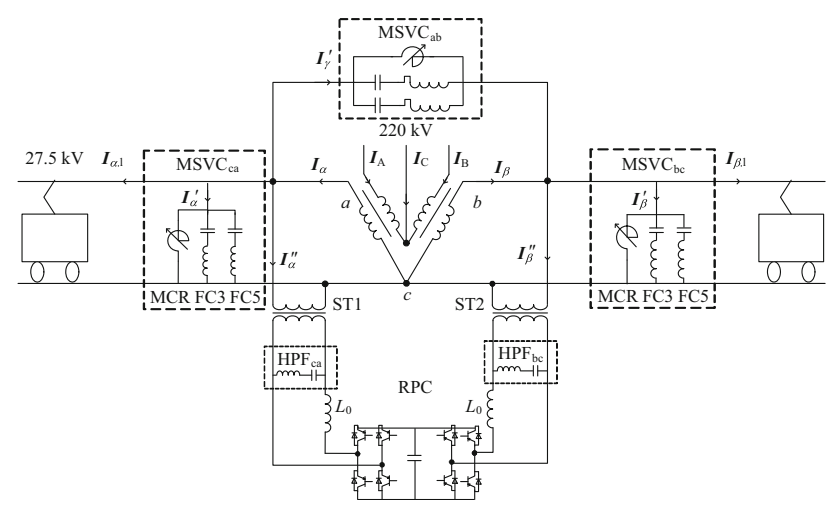

Fig. 2 Topology diagram of EHCS
Traction transformer is the $\mathrm{V} / \mathrm{V}$ transformer, which steps down $220 \mathrm{kV}$ high voltage into $27.5 \mathrm{kV} . \mathrm{MSVC}_{\mathrm{ca}}$, $\mathrm{MSVC}_{\mathrm{bc}}$ and $\mathrm{MSVC}_{\mathrm{ab}}$ is three sets of MSVC, which are installed at the traction transformer secondary side. FC3 and FC5 mean the third and the fifth power filters. Small capacity RPC in series with output reactance $L_{0}$ and in parallel with high-pass filter HPF at the output port is installed on both ends of the traction power supply arm through step-down transformers ST1 and ST2, compensating for rapidly changing component of load.

\subsection{Vector analysis of the load negative sequence and reactive current}

The load currents are composed of their active and reactive current components respectively:

$\left\{\begin{array}{l}\boldsymbol{I}_{\alpha .1}=\boldsymbol{I}_{\alpha \mathrm{l.p}}+\boldsymbol{I}_{\alpha \mathrm{l.q}} \\ \boldsymbol{I}_{\beta .1}=\boldsymbol{I}_{\beta 1 . \mathrm{p}}+\boldsymbol{I}_{\beta 1 . \mathrm{q}}\end{array}\right.$

According to the symmetrical component method, the following formulas can be deduced.

$$
\left\{\begin{array}{l}
\boldsymbol{I}_{\alpha \mathrm{l} . \mathrm{p}}^{-}=\frac{1}{\sqrt{3}} \boldsymbol{I}_{\alpha \mathrm{l} \mathrm{p}} \angle\left(-30^{\circ}\right) \\
\boldsymbol{I}_{\beta \mathrm{l} \mathrm{p}}^{-}=\frac{1}{\sqrt{3}} \boldsymbol{I}_{\beta \mathrm{l} \mathrm{p}} \angle\left(-90^{\circ}\right)
\end{array}\right.
$$

where $\boldsymbol{I}_{\alpha 1 . p}^{-}, \mathrm{I}_{\beta 1 . p}^{-}$are the negative sequence components of $\boldsymbol{I}_{\alpha \mathrm{l} . \mathrm{p}}^{-}$and $\mathrm{I}_{\beta 1 . \mathrm{p}}$.

To solve the negative sequence and reactive power problem caused by the traction load, EHCS shall satisfy the following equation:

$$
\left\{\begin{array}{c}
\boldsymbol{I}_{\alpha \mathrm{l} . \mathrm{p}}^{-}+\boldsymbol{I}_{\beta 1 . \mathrm{p}}^{-}=-\boldsymbol{I}_{\mathrm{EHCS}}^{-} \\
\boldsymbol{I}_{\alpha \mathrm{l.q}}+\boldsymbol{I}_{\beta 1 . \mathrm{q}}=-\boldsymbol{I}_{\mathrm{EHCS} . \mathrm{q}}
\end{array}\right.
$$

where $\boldsymbol{I}_{\mathrm{EHCS}}$ is the negative sequence components of EHCS to compensate the load active current negative sequence component; and $\boldsymbol{I}_{\text {EHCS.q }}$ is the current of EHCS to compensate the load reactive current.

Assuming the maximum load active currents on both sides are $\boldsymbol{I}_{\alpha 1 \text {.pm }}$ and $\boldsymbol{I}_{\beta 1 . p m}$, the maximum negative sequence components of them are $\boldsymbol{I}_{\alpha 1 . \mathrm{pm}}^{-}$and $\boldsymbol{I}_{\beta 1 . \mathrm{pm}}^{-}$, and the maximum load reactive currents are $\boldsymbol{I}_{\alpha 1 . \mathrm{pm}}$ and $\boldsymbol{I}_{\beta 1 . \mathrm{pm}}$. Then, the vector area of the negative sequence components and the load reactive current is shown in Fig. 3a and Fig. $3 b$.

\subsection{Negative sequence compensation principle of MSVC}

As shown in Fig. 4, six different negative sequence component vectors can be produced by the MSVC compensating network. Therefore, the compensation scope of MSVC is the area surrounded by blue solid lines. However, only the blue shaded diamond is enough to compensate the 


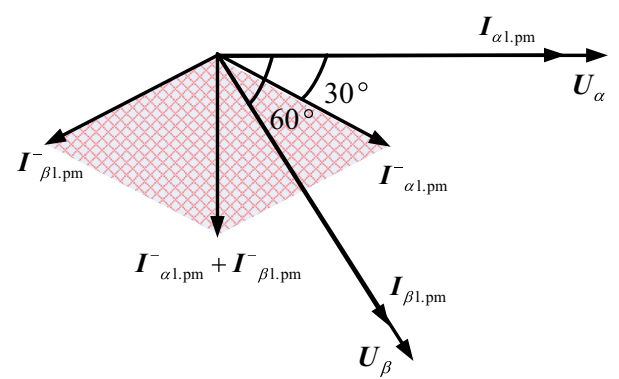

(a) Negative sequence components

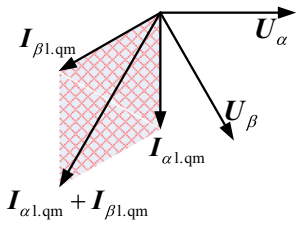

(b) Load reactive current

Fig. 3 Vector area of the negative sequence components and the load reactive curren

red shaded diamond produced by the load current, thus MSVC just needs to provide four negative sequence components indicated by the four blue vectors.

According to the symmetrical component method, the negative sequence compensation current that MSVC compensation system can produce is:

$\left[\begin{array}{l}\boldsymbol{I}_{\mathrm{MSVC}}^{-} \\ \boldsymbol{I}_{\mathrm{MSVC}}^{+}\end{array}\right]=\frac{\sqrt{3}}{3}\left[\begin{array}{ccc}\frac{\sqrt{3}}{2}-j \frac{1}{2} & -j & \frac{\sqrt{3}}{2}+j \frac{1}{2} \\ \frac{\sqrt{3}}{2}+j \frac{1}{2} & j & \frac{\sqrt{3}}{2}-j \frac{1}{2}\end{array}\right]\left[\begin{array}{c}\boldsymbol{I}_{\alpha \mathrm{p}}^{\prime} \\ \boldsymbol{I}_{\beta \mathrm{p}}^{\prime} \\ \boldsymbol{I}_{\gamma \mathrm{p}}^{\prime}\end{array}\right]$

$\boldsymbol{I}_{\alpha \mathrm{p}}^{\prime}, \boldsymbol{I}_{\beta \mathrm{p}}^{\prime}$ and $\boldsymbol{I}_{\gamma \mathrm{p}}^{\prime}$ denote the output current of each phase of MSVC.

It can be seen from (9) that the negative sequence components generated by MSVC have three components $\boldsymbol{I}_{\alpha \mathrm{p}}^{\prime-}, \boldsymbol{I}_{\beta \mathrm{p}}^{\prime-}$ and $\boldsymbol{I}_{\gamma \mathrm{p}}^{\prime-}$ :

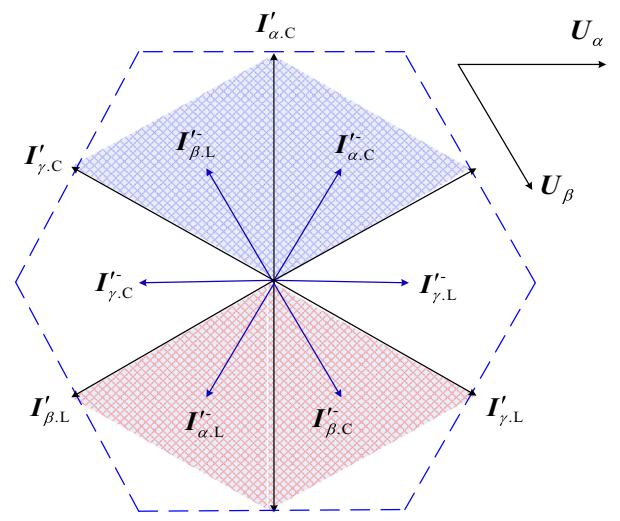

Fig. 4 Negative sequence compensation vector diagram of threephase MSVC compensation network

$$
\left\{\begin{array}{l}
\boldsymbol{I}_{\alpha \mathrm{p}}^{\prime-}=\frac{\sqrt{3}}{3}\left(\frac{\sqrt{3}}{2}-j \frac{1}{2}\right) \cdot \boldsymbol{I}_{\alpha \mathrm{p}}^{\prime}=\frac{\sqrt{3}}{3} \boldsymbol{I}_{\alpha \mathrm{p}}^{\prime} \angle-30^{\circ} \\
\boldsymbol{I}_{\beta \mathrm{p}}^{\prime-}=-\frac{\sqrt{3}}{3} j \cdot \boldsymbol{I}_{\beta \mathrm{p}}^{\prime}=\frac{\sqrt{3}}{3} \boldsymbol{I}_{\beta \mathrm{p}}^{\prime} \angle-90^{\circ} \\
\boldsymbol{I}_{\gamma \mathrm{p}}^{\prime-}=\frac{\sqrt{3}}{3}\left(\frac{\sqrt{3}}{2}+j \frac{1}{2}\right) \cdot \boldsymbol{I}_{\gamma \mathrm{p}}^{\prime}=\frac{\sqrt{3}}{3} \boldsymbol{I}_{\gamma \mathrm{p}}^{\prime} \angle 30^{\circ}
\end{array}\right.
$$

Assuming that the system satisfies the requirement of the power factor:

$Q_{\alpha}^{\prime}+Q_{\beta}^{\prime}+Q_{\gamma}^{\prime}=U_{\alpha} I_{\alpha \mathrm{p}}^{\prime}+U_{\beta} I_{\beta \mathrm{p}}^{\prime}+U_{\gamma} I_{\gamma \mathrm{p}}^{\prime}=0$

The negative sequence compensation current of MSVC compensation system must meet the following requirements: $I_{\alpha \mathrm{p}}^{\prime}+I_{\beta \mathrm{p}}^{\prime}+I_{\gamma \mathrm{p}}^{\prime}=0 . I_{\alpha \mathrm{p}}^{\prime}, I_{\beta \mathrm{p}}^{\prime}, I_{\gamma \mathrm{p}}^{\prime}$ are RMS of $\boldsymbol{I}_{\alpha \mathrm{p}}^{\prime}, \boldsymbol{I}_{\beta \mathrm{p}}^{\prime}$ and $\boldsymbol{I}_{\gamma \mathrm{p}}^{\prime}$, respectively.

Moreover, MSVC should output the corresponding negative sequence compensation current component, which can create the negative sequence components that equals to negative sequence current of the load with the opposite sign. That is:

$\left\{\begin{array}{l}\frac{1}{2 \sqrt{3}} I_{\alpha \mathrm{p}}^{\prime}+\frac{1}{2 \sqrt{3}} I_{\beta \mathrm{p}}^{\prime}-\frac{1}{\sqrt{3}} I_{\gamma \mathrm{p}}^{\prime}=\frac{1}{2} \boldsymbol{I}_{\alpha \mathrm{ll.p}}-\frac{1}{2} \boldsymbol{I}_{\beta 1 . \mathrm{p}} \\ -\frac{1}{2} I_{\alpha \mathrm{p}}^{\prime}+\frac{1}{2} I_{\beta \mathrm{p}}^{\prime}=\frac{1}{2 \sqrt{3}} \boldsymbol{I}_{\alpha \mathrm{l} . \mathrm{p}}+\frac{1}{2 \sqrt{3}} \boldsymbol{I}_{\beta \mathrm{l} . \mathrm{p}}\end{array}\right.$

According to (11) and (12), the negative sequence compensation current component reference signal of each phase of MSVC can be obtained as follows:

$$
\left\{\begin{array}{l}
\boldsymbol{I}_{\alpha \mathrm{p}}^{\prime}=\frac{1}{\sqrt{3}} \boldsymbol{I}_{\beta 1 . \mathrm{p}} \angle 150^{\circ} \\
\boldsymbol{I}_{\beta \mathrm{p}}^{\prime}=\frac{1}{\sqrt{3}} \boldsymbol{I}_{\alpha \mathrm{l} \mathrm{p}} \angle-150^{\circ} \\
\boldsymbol{I}_{\gamma \mathrm{p}}^{\prime}=\frac{1}{\sqrt{3}} \boldsymbol{I}_{\alpha \mathrm{l} \mathrm{p}} \angle-30^{\circ}+\frac{1}{\sqrt{3}} \boldsymbol{I}_{\beta 1 . \mathrm{p}} \angle 30^{\circ}
\end{array}\right.
$$

\subsection{Negative sequence compensation principle of RPC}

According to the symmetrical component method, the negative sequence components of RPC output current on both sides are:

$$
\left\{\begin{array}{l}
\boldsymbol{I}_{\alpha}^{\prime \prime-}=\frac{\sqrt{3}}{3}\left(\frac{\sqrt{3}}{2}-j \frac{1}{2}\right) \cdot \boldsymbol{I}_{\alpha}^{\prime \prime}=\frac{\sqrt{3}}{3} \boldsymbol{I}_{\alpha}^{\prime \prime} \angle-30^{\circ} \\
\boldsymbol{I}_{\beta}^{\prime \prime-}=-\frac{\sqrt{3}}{3} j \cdot \boldsymbol{I}_{\beta}^{\prime \prime}=\frac{\sqrt{3}}{3} \boldsymbol{I}_{\beta}^{\prime \prime} \angle-90^{\circ}
\end{array}\right.
$$

The output current of RPC's $\alpha$-phase and $\beta$-phase inverters are composed of active component and reactive component, then: 
$\left\{\begin{array}{l}\boldsymbol{I}_{\alpha}^{\prime \prime}=I_{\alpha . \mathrm{p}}^{\prime \prime} \angle 0^{\circ}+I_{\alpha . \mathrm{q}}^{\prime \prime} \angle 90^{\circ} \\ \boldsymbol{I}_{\beta}^{\prime \prime}=I_{\beta . \mathrm{p}}^{\prime \prime} \angle 120^{\circ}+I_{\beta . \mathrm{q}}^{\prime \prime} \angle 30^{\circ}\end{array}\right.$

Without considering the loss of RPC, and assuming that RPC alone is able to keep stable DC bus voltage, active power absorbed from RPC's one side and active power output from the other side must be equal: $I_{\alpha . \mathrm{p}}^{\prime \prime}=I_{\beta . \mathrm{p}}^{\prime \prime}$, and the inductive reactive and capacitive reactive power on both sides of the RPC's converter outputs should be the same.

The negative sequence component produced by RPC is:

$$
\begin{aligned}
\boldsymbol{I}^{\prime \prime-} & =\boldsymbol{I}_{\alpha}^{\prime \prime-}+\boldsymbol{I}_{\beta}^{\prime \prime-} \\
& =\frac{\sqrt{3}}{3}\left(I_{\alpha . \mathrm{p}}^{\prime \prime} \angle-30^{\circ}+I_{\alpha . \mathrm{q}}^{\prime \prime} \angle 60^{\circ}+I_{\beta . \mathrm{p}}^{\prime \prime} \angle 30^{\circ}+I_{\beta . \mathrm{q}}^{\prime \prime} \angle-60^{\circ}\right) \\
& =\frac{\sqrt{3}}{3}\left(I_{\alpha . \mathrm{p}}^{\prime \prime} \angle-30^{\circ}+I_{\alpha . \mathrm{p}}^{\prime \prime} \angle 30^{\circ}+I_{\alpha \cdot \mathrm{q}}^{\prime \prime} \angle 60^{\circ}+I_{\alpha . \mathrm{q}}^{\prime \prime} \angle 120^{\circ}\right) \\
& =I_{\alpha . \mathrm{p}}^{\prime \prime} \angle 0^{\circ}+I_{\alpha . \mathrm{q}}^{\prime \prime} \angle 90^{\circ}=\boldsymbol{I}_{\alpha}^{\prime \prime}
\end{aligned}
$$

The negative sequence component produced by RPC and the output current of RPC's $\alpha$-phase are the same.

When $\alpha$-phase converter absorbs active power, namely, $I_{\alpha . \mathrm{p}}^{\prime \prime} \geq 0$, the compensation range of the negative sequence current is the left semicircle in Fig. 5a. When $\alpha$-phase inverter outputs active power: $I_{\alpha . \mathrm{p}}^{\prime \prime} \leq 0$, the compensation range of the negative sequence current is the right semicircle in Fig. 5b. In conclusion, the negative sequence current that the RPC can compensate is a circle with the radius as the RPC's rated current $I_{\alpha}^{\prime \prime}$.

\subsection{Negative sequence compensation analysis of EHCS}

The negative sequence compensation operation area of EHCS can be deduced, as shown in Fig. 6.

According to previous sections, the RPC compensation area is a circle with the radius as the RPC's rated current, and the MSVC compensation area is the pentagon which is

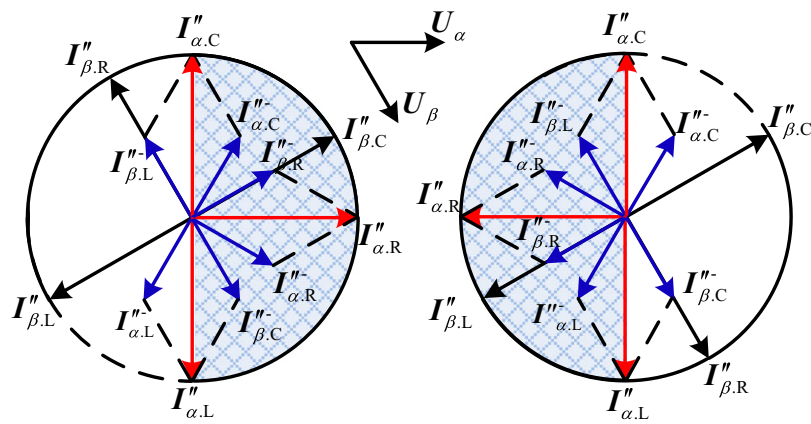

(a) $\alpha$-phase absorbs active power (b) $\alpha$-phase outputs active power

Fig. 5 Negative sequence current vector produced by RPC composed of its four negative sequence components. Therefore, the area surrounded by blue solid lines is the scope that EHCS can compensate. While the area of negative sequence component produced by the load active current is shown as the red shaded diamond so that EHCS should just output corresponding current to create an area which is symmetrical with the load negative sequence component area, that is, the blue shade diamond to eliminate the high-speed railway negative sequence problem produced by asymmetric load.

\section{Minimum capacity of EHCS}

\subsection{Minimum capacity of MSVC in the complete compensation}

In order to reduce the compensation capacity cost and improve the local dynamic response of EHCS, the complete compensation strategy of EHCS is discussed in this section.

Because RPC costs about 8 times MSVC per unit capacity [15], a small capacity RPC is used to realize economical in this paper. The extreme environment is analyzed, namely, the active load current on ac side reaches the maximum, the active load current on bc side is zero, so that RPC cannot balance the active current load on both sides.

Assuming the active current RMS value that RPC transfers is $I_{\text {RPC.p }}$, then the active current RMS value on both supply arm sides after the active current is transferred are:

$\left\{\begin{array}{l}I_{\alpha 1 . \mathrm{p}}^{\prime}=I_{\alpha 1 . \mathrm{p}}-I_{\mathrm{RPC} . \mathrm{p}} \\ I_{\beta 1 . \mathrm{p}}^{\prime}=I_{\beta 1 . \mathrm{p}}+I_{\mathrm{RPC} . \mathrm{p}}\end{array}\right.$

where $I_{\alpha 1 . p}^{\prime}$ and $I_{\beta 1 . p}^{\prime}$ are RMS of active currents of two power supply arms after transferring active power.

The negative sequence current produced by them are:

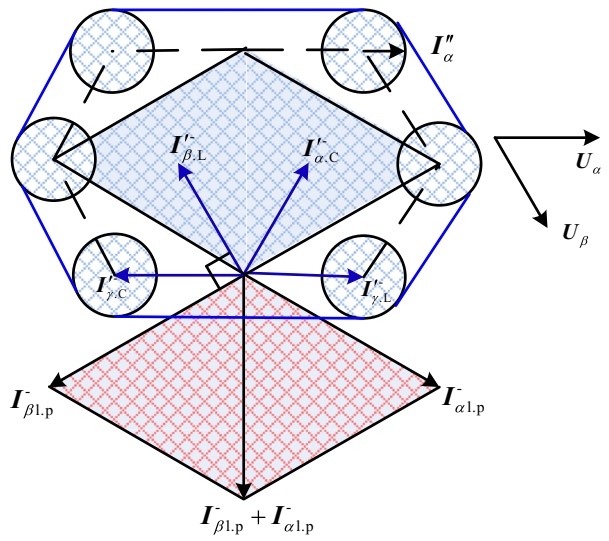

Fig. 6 Negative sequence compensation of EHCS 
$\left\{\begin{array}{l}I_{\alpha 1 . \mathrm{p}}^{\prime-}=\frac{1}{\sqrt{3}}\left(I_{\alpha 1 . \mathrm{p}}-I_{\mathrm{RPC} . \mathrm{p}}\right) \\ I_{\beta 1 . \mathrm{p}}^{\prime-}=\frac{1}{\sqrt{3}}\left(I_{\beta 1 . \mathrm{p}}+I_{\mathrm{RPC} . \mathrm{p}}\right)\end{array}\right.$

According to section 3.2, MSVC should output the corresponding compensation current component $\boldsymbol{I}_{\alpha}^{\prime}, \boldsymbol{I}_{\beta}^{\prime}$ and $\boldsymbol{I}_{\gamma}^{\prime}$, which can create the negative sequence components that equals to the load negative sequence current with the opposite sign. The MSVC required reactive power compensation current RMS value of each phase are:

$$
\left\{\begin{array}{l}
I_{\alpha}^{\prime}=\frac{1}{\sqrt{3}}\left(I_{\beta 1 . \mathrm{p}}+I_{\mathrm{RPC} . \mathrm{p}}\right) \\
I_{\beta}^{\prime}=\frac{1}{\sqrt{3}}\left(I_{\alpha 1 \cdot \mathrm{p}}-I_{\mathrm{RPC} . \mathrm{p}}\right) \\
I_{\gamma}^{\prime}=\frac{1}{\sqrt{3}}\left(I_{\alpha 1 \cdot \mathrm{p}}-I_{\mathrm{RPC} . \mathrm{p}}\right)-\frac{1}{\sqrt{3}}\left(I_{\beta 1 . \mathrm{p}}+I_{\mathrm{RPC} . \mathrm{p}}\right)
\end{array}\right.
$$

The active power that RPC transferred is $P_{\mathrm{RPC}}=I_{\mathrm{RPC} . \mathrm{p}} \cdot U$, thus the MSVC required compensation $\operatorname{capacity}\left(Q_{\alpha . \mathrm{MSVC}}, Q_{\beta \text {.MSVC}}, Q_{\gamma \text {.MSVC }}\right)$ of each phase are:

$$
\left\{\begin{array}{l}
Q_{\alpha . \mathrm{MSVC}}=\frac{1}{\sqrt{3}}\left(I_{\beta 1 . \mathrm{p}}+I_{\mathrm{RPC} . \mathrm{p}}\right) \cdot U-\sqrt{S_{\mathrm{RPC}}^{2}-P_{\mathrm{RPC}}^{2}} \\
Q_{\beta \text {.MSVC }}=\frac{1}{\sqrt{3}}\left(I_{\alpha 1 . \mathrm{p}}-I_{\mathrm{RPC} . \mathrm{p}}\right) \cdot U-\sqrt{S_{\mathrm{RPC}}^{2}-P_{\mathrm{RPC}}^{2}} \\
Q_{\gamma \cdot \mathrm{MSVC}}=\frac{2}{\sqrt{3}}\left(I_{\alpha 1 . \mathrm{p}}-I_{\beta 1 . \mathrm{p}}-2 I_{\mathrm{RPC} . \mathrm{p}}\right) \cdot U
\end{array}\right.
$$

The total MSVC required compensation capacity is,

$$
\begin{aligned}
Q_{\mathrm{Total}}= & \frac{2}{\sqrt{3}}\left(I_{\alpha 1 . \mathrm{p}}-I_{\mathrm{RPC} . \mathrm{p}}\right) \cdot U-2 \sqrt{S_{\mathrm{RPC}}^{2}-P_{\mathrm{RPC}}^{2}} \\
& +\frac{2}{\sqrt{3}}\left(I_{\alpha 1 . \mathrm{p}}-I_{\beta 1 . \mathrm{p}}-2 I_{\mathrm{RPC} . \mathrm{p}}\right) \cdot U=\frac{4}{\sqrt{3}} I_{\alpha 1 . \mathrm{p}} \cdot U \\
& -\frac{2}{\sqrt{3}} I_{\beta 1 . \mathrm{p}} \cdot U-2 \sqrt{3} P_{\mathrm{RPC}}-2 \sqrt{S_{\mathrm{RPC}}^{2}-P_{\mathrm{RPC}}^{2}}
\end{aligned}
$$

Take the derivative of $P_{\mathrm{RPC}}$, and then it can be concluded that the total MSVC required compensation capacity is the minimum when $\frac{P_{\mathrm{RPC}}}{\sqrt{S_{\mathrm{RPC}}^{2}-P_{\mathrm{RPC}}^{2}}}=\frac{P_{\mathrm{RPC}}}{Q_{\mathrm{RPC}}}=\sqrt{3}$, that is:

$Q_{\text {TotalMin }}=\frac{4}{\sqrt{3}} \boldsymbol{I}_{\alpha \mathrm{l} . \mathrm{p}} \cdot U-\frac{2}{\sqrt{3}} \boldsymbol{I}_{\beta \mathrm{l} . \mathrm{p}} \cdot U-4 S$

\subsection{Constraints of the optimization model}

According to the relative standard [5], the negative sequence voltage unbalanced degree should be less than $2 \%$, not more than $4 \%$ within a short time. The negative sequence voltage unbalanced degree value which is caused by each user connected to a common connection point is commonly limit to $1.3 \%$, not more than $2.6 \%$ within a short time. Above $100 \mathrm{kVA}$ high voltage power supply power factor for users should be above 0.90 .

$\left\{\begin{array}{l}0 \leq \varepsilon_{U} \leq \xi \\ 0.9 \leq \cos \varphi \leq 1\end{array}\right.$

where $\varepsilon_{U}=\left|U_{-} / U_{+}\right|$is voltage unbalanced degree; $U_{+}$and $U_{-}$the positive and negative sequence voltage; $\zeta$ the upper limit of voltage unbalanced degree; $\cos \varphi$ the power factor after compensation.

\subsection{Optimal installed capacity under a fixed capacity of RPC}

With a fixed RPC capacity and constraints listed in (22), the strategy is to allocate the reactive power output of each phase of MSVCs so as to minimize the total MSVC compensation capacity.

An extreme case is analyzed below. When the $\alpha$-phase load current reaches the maximum and the $\beta$-phase load current is 0 , that is, $\boldsymbol{I}_{\alpha .1}=\boldsymbol{I}_{\alpha \mathrm{l} . \mathrm{pm}}+\boldsymbol{I}_{\alpha \mathrm{l} . \mathrm{qm},}, \quad \boldsymbol{I}_{\beta .1}=0$. According to the former conclusion, the current RMS value on both sides of RPC exist the following relationship, $I_{\alpha . \mathrm{p}}^{\prime \prime}=I_{\beta . \mathrm{p}}^{\prime \prime}$, and $I_{\alpha . \mathrm{p}}^{\prime \prime} / I_{\alpha \cdot \mathrm{q}}^{\prime \prime}=\sqrt{3}$.

Then the load can be decomposed into two independent networks, which is shown in the Table 1.

The analysis is made on two networks above. Network 1 is balanced network that only contains positive sequence component, and the power factor is 1 . Network 2 is unbalanced network which should be compensated by MSVC for reactive power and negative sequence compensation.

In the complete compensation strategy, the MSVC required compensation current of each phase are :

$I_{\alpha}^{\prime}=I_{\alpha 1 . \mathrm{qm}}, \quad I_{\beta}^{\prime}=\frac{I_{\alpha 1 . \mathrm{qm}}-2 I_{\alpha . \mathrm{p}}^{\prime \prime}}{\sqrt{3}}, \quad I_{\gamma}^{\prime}=\frac{I_{\alpha 1 . \mathrm{qm}}-2 I_{\alpha . \mathrm{p}}^{\prime \prime}}{\sqrt{3}}$

For the convenience of description, assuming the ratio of active power that RPC transferred to the load active

Table 1 Two independent networks of load

\begin{tabular}{llll}
\hline Network & $\mathrm{AB}$ & $\mathrm{BC}$ & $\mathrm{AC}$ \\
\hline 1 & $\boldsymbol{I}_{\alpha 1}=0$ & $\boldsymbol{I}_{\beta 1}=\boldsymbol{I}_{\beta . \mathrm{p}}^{\prime \prime}+\boldsymbol{I}_{\beta . \mathrm{q}}^{\prime \prime}$ & $\boldsymbol{I}_{\gamma 1}=\boldsymbol{I}_{\alpha . \mathrm{p}}^{\prime \prime}+\boldsymbol{I}_{\alpha . \mathrm{q}}^{\prime \prime}$ \\
2 & $\boldsymbol{I}_{\alpha 2}=0$ & $\boldsymbol{I}_{\beta 2}=0$ & $\boldsymbol{I}_{\gamma 2}=\boldsymbol{I}_{\alpha 1 . \mathrm{pm}}^{\prime \prime}-2 \boldsymbol{I}_{\alpha . \mathrm{p}}^{\prime \prime}+\boldsymbol{I}_{\alpha 1 . \mathrm{qm}}$
\end{tabular}


power is $a=P_{\mathrm{RPC}} / P_{\max }$. Then the MSVC required compensation capacity of each phase are:

$$
\left\{\begin{array}{l}
Q_{\alpha . \mathrm{MSVC}}=h_{3} U(1-2 a) I_{\alpha 1 . \mathrm{pm}}-U I_{\alpha 1 . \mathrm{qm}} \\
Q_{\beta . \mathrm{MSVC}}=h_{2} U(1-2 a) I_{\alpha 1 . \mathrm{pm}} \\
Q_{\gamma . \mathrm{MSVC}}=-h_{1} U(1-2 a) I_{\alpha 1 \mathrm{pm}}
\end{array}\right.
$$

where $a<0.5 ; h_{i} \geq 0$; and $i=1,2,3$.

Setting the limit of the current unbalanced degree in system as $\mu=\xi S_{\mathrm{d}} / S_{\mathrm{L}}$, the compensation goal is to minimize the total MSVC compensation capacity under the premise of meeting current unbalanced degree and power factor requirements. Therefore, the mathematical optimization capacity model is obtained as follows:

$$
\begin{cases}\text { Min } & f\left(Q_{\alpha . \mathrm{MSVC}}, Q_{\beta . \mathrm{MSVC}}, Q_{\gamma . \mathrm{MSVC}}\right)= \\ & Q_{\beta . \mathrm{MSVC}}-Q_{\alpha . \mathrm{MSVC}}-Q_{\gamma . \mathrm{MSVC}} \\ \text { s.t. } & Q_{\gamma \cdot \mathrm{MSVC}}+Q_{\beta . \mathrm{MSV}}+Q_{\alpha . \mathrm{MSVC}}+Q_{\max } \geq 0 \\ & 0 \leq \varepsilon_{I} \leq \mu=\xi \cdot \frac{S_{\mathrm{d}}}{S_{\mathrm{L}}}=\xi \cdot \frac{S_{\mathrm{d}}}{S_{\alpha .1}} \\ & C \leq \cos \varphi \leq 1\end{cases}
$$

The compensation capacity of each phase can be obtained:

$$
\left\{\begin{aligned}
Q_{\alpha . \mathrm{MSVC}} & =\left[\frac{\sqrt{1-C^{2}}+\mu}{3 C(1-2 a)}\right] U I_{\alpha 1 . \mathrm{pm}}(1-2 a)-U I_{\alpha 1 . \mathrm{qm}} \\
Q_{\beta . \mathrm{MSVC}} & =\left[\frac{1}{\sqrt{3}}+\frac{\sqrt{1-C^{2}}-2 \mu}{3 C(1-2 a)}\right] U I_{\alpha 1 . \mathrm{pm}}(1-2 a) \\
Q_{\gamma . \mathrm{MSVC}} & =-\left[\frac{1}{\sqrt{3}}-\frac{\sqrt{1-C^{2}}+\mu}{3 C(1-2 a)}\right] U I_{\alpha 1 . \mathrm{pm}}(1-2 a)
\end{aligned}\right.
$$

The total minimum capacity of compensation is:

$$
Q_{\min }=\left(\frac{2}{\sqrt{3}}-\frac{\sqrt{1-C^{2}}+4 \mu}{3 C(1-2 a)}\right) U I_{\alpha 1 . \mathrm{pm}}(1-2 a)+U I_{\alpha 1 . \mathrm{qm}}
$$

\section{Control strategy of EHCS}

According to the analysis hereinabove, the intent current of two power supply arm can be calculated by using instantaneous power detection method [16]. Assuming the voltage of two supply arm are $\boldsymbol{e}_{\alpha}(t)=\sin (\omega t-\pi / 6)$ and $\boldsymbol{e}_{\beta}(t)=\sin (\omega t-\pi / 2)$ respectively, the load current of two power supply arm are $i_{\alpha \mathrm{L}}(t)$ and $i_{\beta \mathrm{L}}(t)$, which can be expressed as follow by Fourier decomposition.

$$
\left\{\begin{aligned}
\boldsymbol{i}_{\alpha \mathrm{L}}(t)= & I_{\alpha \mathrm{p}} \sin \left(\omega t-\frac{\pi}{6}\right)-I_{\alpha \mathrm{q}} \cos \left(\omega t-\frac{\pi}{6}\right) \\
& +\sum_{h=2}^{\infty} I_{\alpha \mathrm{h}} \sin \left(h \omega t+\varphi_{\alpha \mathrm{h}}\right) \\
\boldsymbol{i}_{\beta \mathrm{L}}(t)= & I_{\beta \mathrm{p}} \sin \left(\omega t-\frac{\pi}{2}\right)-I_{\beta \mathrm{q}} \cos \left(\omega t-\frac{\pi}{2}\right) \\
& +\sum_{h=2}^{\infty} I_{\beta \mathrm{h}} \sin \left(h \omega t+\varphi_{\beta \mathrm{h}}\right)
\end{aligned}\right.
$$

$I_{\alpha \mathrm{p}}$ and $I_{\beta \mathrm{p}}$ are fundamental wave load active current amplitudes of two power supply arms, respectively. $I_{\alpha \mathrm{q}}$ and $I_{\beta \mathrm{q}}$ are amplitudes of fundamental components of load reactive current of two power supply arms, respectively. Bisides, $I_{\alpha \mathrm{h}} \sin \left(h \omega t+\varphi_{\alpha \mathrm{h}}\right) \quad$ and $\quad I_{\beta \mathrm{h}} \sin \left(h \omega t+\varphi_{\beta \mathrm{h}}\right)$ are harmonic components of two supply arms.

According to the instantaneous power detection method, $\boldsymbol{i}_{\alpha \mathrm{L}}(t)$ is multiplied by the voltage synchronization signal, and then the half of the fundamental wave active current amplitude can be extracted from its product by a low-pass filter, namely, $\sqrt{2} / 2 \mathrm{I}_{\alpha \mathrm{p}}$. Similarly, $\boldsymbol{i}_{\alpha \mathrm{L}}(t)$ is multiplied by the signal that lags behind the voltage signal $\pi / 2$, and then the half of the fundamental wave reactive current amplitude can be extracted from its product by a low-pass filter, namely, $\sqrt{2} / 2 \mathrm{I}_{\alpha \mathrm{q}}$. In the same way, the half of the fundamental wave active current amplitude of $\boldsymbol{i}_{\beta \mathrm{L}}(t)$ and the half of the fundamental wave reactive current amplitude of $\boldsymbol{i}_{\beta \mathrm{L}}(t)$ can be calculated.

In order to eliminate the negative sequence and reactive current, the expected current for power supply arm after compensation is [8]:

$$
\left\{\begin{array}{l}
i_{\mathrm{a}}^{\exp }(t)=\frac{\sqrt{2}}{2} I_{\mathrm{L} 1 \mathrm{p}} \sin \left(\omega t-\frac{\pi}{6}\right)+\frac{\sqrt{2}}{2 \sqrt{3}} I_{\mathrm{L} 1 \mathrm{p}} \cos \left(\omega t-\frac{\pi}{6}\right) \\
i_{\mathrm{b}}^{\exp }(t)=\frac{\sqrt{2}}{2} I_{\mathrm{L} 1 \mathrm{p}} \sin \left(\omega t-\frac{\pi}{2}\right)-\frac{\sqrt{2}}{2 \sqrt{3}} I_{\mathrm{L} 1 \mathrm{p}} \cos \left(\omega t-\frac{\pi}{2}\right)
\end{array}\right.
$$

The calculating follow for expected current for power supply arm, which are expressed as $I_{\mathrm{a}}^{\exp }(t)$ and $I_{\mathrm{b}}^{\exp }(t)$, after compensation is shown in Fig. 7.

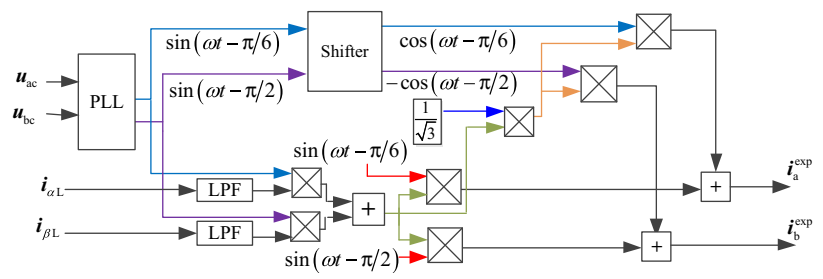

Fig. 7 Calculating follow for expected current of power supply arm 


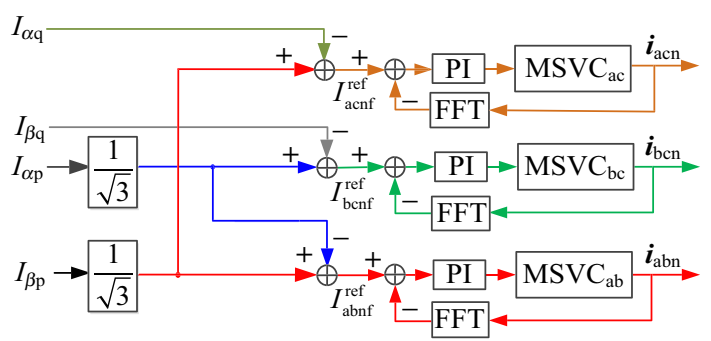

Fig. 8 Control chart of MSVC

In order to obtain compensating current reference of MSVC, the fundamental wave active current amplitude and the fundamental wave reactive current amplitude of two power supply arm load current, which can be calculated using instantaneous power detection method, are needed. According to the analysis of MSVC hereinabove, the compensating current reference of MSVC, which are expressed as $I_{\mathrm{acnf}}^{\mathrm{ref}}, I_{\mathrm{bcnf}}^{\mathrm{ref}}, I_{\mathrm{abnf}}^{\mathrm{ref}}$, are as follows:

$$
\left\{\begin{array}{l}
I_{\mathrm{acnf}}^{\mathrm{ref}}=\frac{1}{\sqrt{3}} I_{\beta \mathrm{p}}-I_{\alpha \mathrm{q}} \\
I_{\mathrm{bcnf}}^{\mathrm{ref}}=\frac{1}{\sqrt{3}} I_{\mathrm{ap}}-I_{\beta \mathrm{q}} \\
I_{\mathrm{abnf}}^{\mathrm{ref}}=-\frac{1}{\sqrt{3}} I_{\alpha \mathrm{p}}+\frac{1}{\sqrt{3}} I_{\beta \mathrm{p}}
\end{array}\right.
$$

The PI control method is adopted for MSVC control. This control method can achieve the purpose of dynamic tracking reference current well. The control chart is shown in Fig. 8.

In order to transfer active power between two power supply arms, the controller of RPC is supposed to stabilize DC voltage and effectively track the reference current. In order to make two converters of RPC work normally, it is necessary to obtain a stable DC voltage.

Therefore, the RPC reference control signal $\boldsymbol{i}_{\mathrm{ac}}^{\text {ref }}(t)$ and $i_{\mathrm{bc}}^{\text {ref }}(t)$ both are composed of RPC reference compensation signal and an additional DC voltage regulatory signal. The additional DC voltage regulatory signal is obtained after comparing the measured value with the reference value of

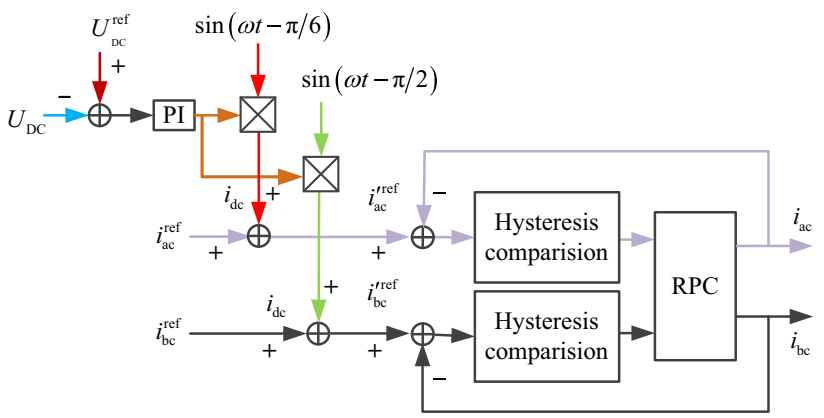

Fig. 9 Control chart of RPC the DC voltage through the PI regulator and then multiplied by the corresponding power supply arm voltage synchronous reference signal.

The hysteresis current control method is adopted to realize real-time tracking to the RPC reference control signal. Thus, this kind of control method can achieve the compensation for negative sequence and reactive current and maintain its own stable operation. The control chart is shown in Fig. 9.

EHCS is made up of MSVC, which compensates negative sequence current caused by steady load and a small amount of reactive power, and RPC, which compensates the fluctuation of negative sequence current caused by fluctuation of load and harmonic current of traction power supply system. The MSVC response speed cannot meet the transient process compensation requirements for electric locomotive load's quick change, especially for the highspeed locomotive load. RPC is power electronics device with a high response speed, which can satisfy the transient process compensation requirements. When the load suddenly increases, the signal detection system detects the load change quickly, and then the MSVC reference current increases immediately, but the reactive compensation current that MSVC offers will has a certain vacancy at this time. From the aforementioned analysis, the RPC reference current is that the expected current minus the load current and MSVC compensation current, so that the EHCS control system automatically uses the RPC capacity to make up for the MSVC reactive vacancy. With the time of the MSVC compensation current gradually increasing and eventually reaching a new reference current, RPC output reactive power gradually decreases and eventually reaches steady state. This hybrid compensation method makes EHCS meet the compensation requirements. The control chart of EHCS is shown in Fig. 10.

\section{Simulations}

\subsection{Parameter setting}

In order to validate the proposed electromagnetic hybrid compensation system feasibility and effectiveness, steady state and transient simulation were carried out by using Matlab/Simulink in this paper.

In simulation, the short-circuit capacity of power system at the connection point is set as 1800 MVA, the rated voltage of the power system between power lines is 220 $\mathrm{kV}$, and power system frequency is $50 \mathrm{~Hz}$. The substation $\mathrm{V} / \mathrm{V}$ transformer is composed of two single-phase transformers, with turn's ratio of $220 \mathrm{kV} / 27.5 \mathrm{kV}$. Since high speed railway power factor is close to 1 or -1 , pure impedance load is used to simulate the high speed rail 


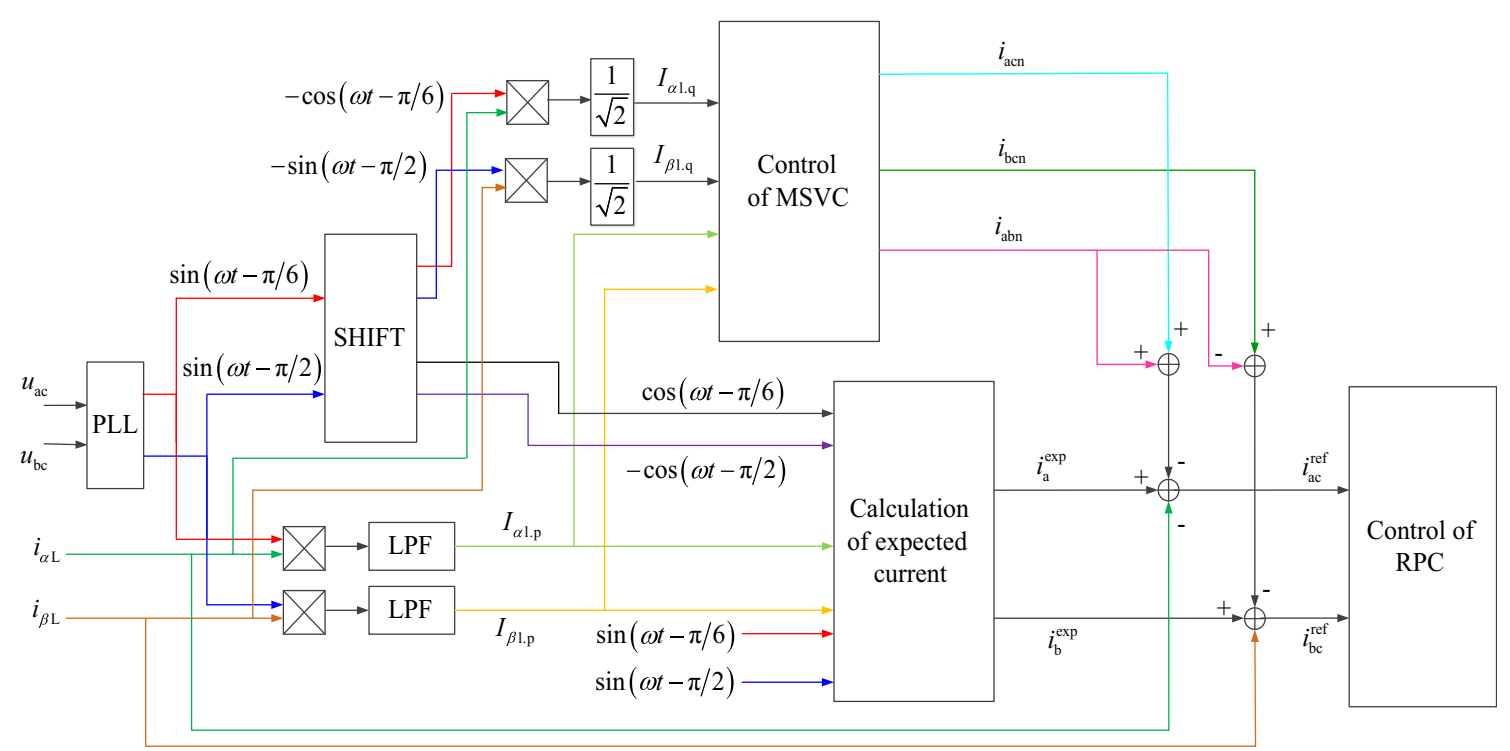

Fig. 10 Control chart of EHCS

Table 2 Parameters of MSVC and RPC for simulation

\begin{tabular}{ll}
\hline Parameter name & Value \\
\hline Three-phase voltage & $220 \mathrm{kV}$ \\
Ratio of V/V transformer & $220 / 27.5 \mathrm{kV}$ \\
Total working capacity of MSVC & $185 \mathrm{MVA}$ \\
Ratio of step-down transformers & $27.5 / 1 \mathrm{kV}$ \\
Working capacity of RPC & $11.55 \mathrm{MVA}$ \\
Output Reactance & $10 \mathrm{mH}$ \\
DC capacitor & $0.1 \mathrm{~F}$ \\
\hline
\end{tabular}

traction locomotive, with its maximum active power as $100 \mathrm{MW}$. MSVC consists of MCR and fixed capacitor group in parallel, the MSVC and RPC parameters are shown in Table 2.

\subsection{Simulation results}

Case 1: the steady state simulation

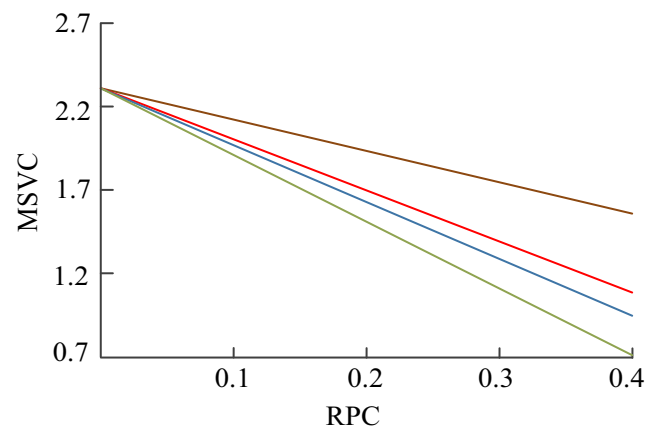

$-P: Q=1: 0-P: Q=\frac{1}{\sqrt{2}}: \frac{1}{\sqrt{2}}-P: Q=\frac{\sqrt{3}}{2}: \frac{1}{2}-P: Q=0: 1$

Fig. 11 Installed capacity of MSVC under the condition of different capacity of RPC with different proportion of its active and reactive power

In this section, the case when the load of AC side achieves the maximum active power $100 \mathrm{MW}$ is simulated, and the results are as shown in Table 3. Assuming the load capacity is base value.

Table 3 Parameters of the case

\begin{tabular}{|c|c|c|c|c|c|c|c|c|c|}
\hline \multirow[t]{2}{*}{$\varepsilon_{U}(\%)$} & & \multicolumn{4}{|c|}{ RPC(MVA) } & \multicolumn{3}{|c|}{ MSVC(MVar) } & \multirow[t]{2}{*}{$\varepsilon_{I}(\%)$} \\
\hline & & $P_{1}$ & $Q_{1}$ & $P_{2}$ & $Q_{2}$ & $Q_{\mathrm{ac}}$ & $Q_{\mathrm{bc}}$ & $Q_{\mathrm{ab}}$ & \\
\hline \multirow[t]{2}{*}{0} & Theory & -10.0 & -5.7 & 10.0 & 5.7 & 0.0 & 46.1 & -46.1 & 0.0 \\
\hline & Simulation & -10.0 & -5.6 & 10.0 & 5.8 & 0.0 & 45.6 & -46.5 & 0.0 \\
\hline \multirow[t]{2}{*}{1.3} & Theory & -10.0 & -5.7 & 10.0 & 5.7 & 7.8 & 30.5 & -38.3 & 23.4 \\
\hline & Simulation & -9.8 & -5.5 & 9.9 & 5.7 & 10.3 & 32.5 & -41.7 & 23.7 \\
\hline \multirow[t]{2}{*}{2.6} & Theory & -10.0 & -5.7 & 10.0 & 5.7 & 15.6 & 14.9 & -30.5 & 46.8 \\
\hline & Simulation & -9.9 & -5.6 & 9.8 & 5.6 & 16.6 & 14.5 & -28.4 & 47.0 \\
\hline
\end{tabular}




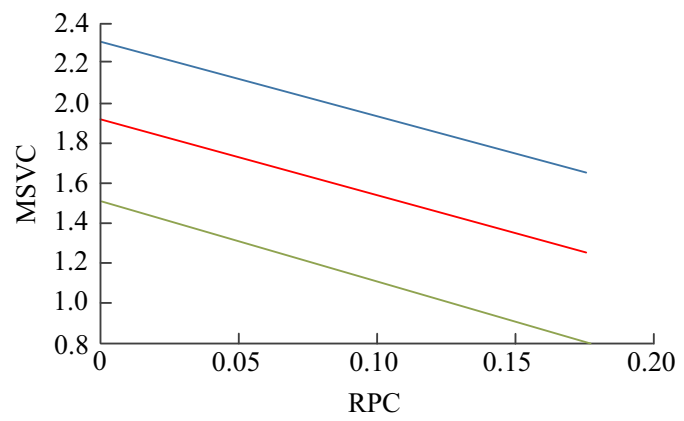

- Complete — Optimization $(\varepsilon \leq 1.3 \%)$ - Optimization $(\varepsilon \leq 2.6 \%)$

Fig. 12 Installed capacity of MSVC under the condition of different capacity of RPC in complete and optimization compensation

Table 4 Installed capacity of different compensation (p.u.)

\begin{tabular}{lll}
\hline & RPC & MSVC \\
\hline Pure RPC & 0.746 & 0 \\
Pure MSVC & 0 & 2.3094 \\
Complete & 0.17321 & 1.6166 \\
Optimization $\left(\varepsilon_{U}=1.3 \%\right)$ & 0.17321 & 1.2266 \\
Optimization $\left(\varepsilon_{U}=2.6 \%\right)$ & 0.17321 & 0.8366
\end{tabular}

Compare the installed capacity of MSVC in the cases that different capacity of RPC are installed in EHCS when different proportion of RPC active and reactive power, namely, $1: 0,1 / \sqrt{2}: 1 / \sqrt{2}, \sqrt{3} / 2: 1 / 2$ and $0: 1$ is assigned. It can be concluded from the Fig.11 that when the proportion of RPC active and reactive power is $\sqrt{3}$, the maximum capacity of MSVC that can be reduced is up to $69.3 \%$.

Compare the installed capacity of MSVC in complete compensation and the optimization compensation under the condition of different capacity of RPC with the proportion of its active and reactive power is $\sqrt{3}$ are installed in EHCS, the result as shown in Fig. 12.

From Fig. 12, we can conclude that the small capacity of RPC can greatly reduce the installed capacity of MSVC in the complete compensation strategy, and the installed capacity of MSVC can also be further reduced in the optimization compensation strategy.

The installed capacity of different compensation strategies are compared in Table 4. Compared with pure MSVC compensation, it is indicated that $29.8 \%$ of MSVC capacity can be reduced in the complete compensation strategy, and $64 \%$ of MSVC capacity can be reduced in the optimization compensation strategy. The cost of RPC is about 8 times as the cost of MSVC [15], thus the EHCS compensation strategy is more economical than pure RPC compensation.

Case 2: transient simulation

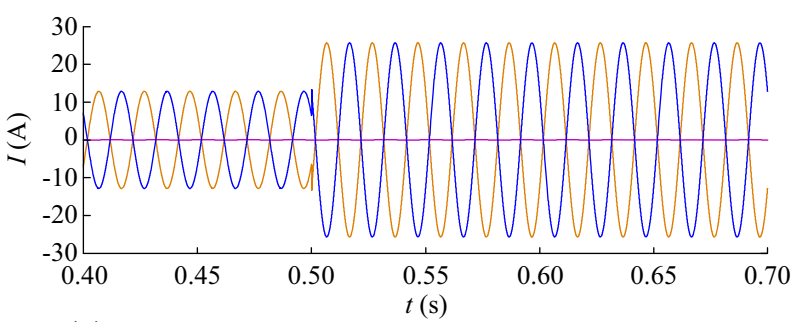

(a) Three-phase current waveform before complete compensation

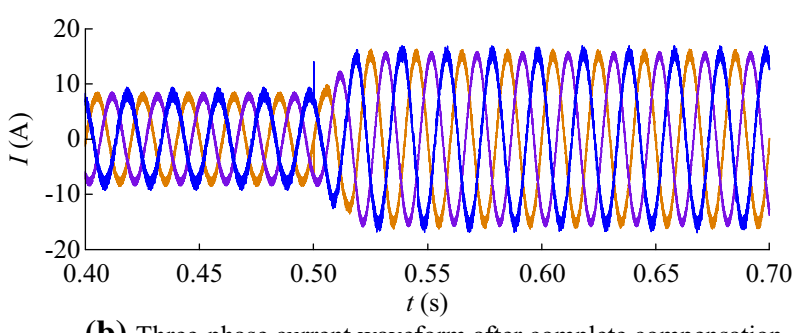

(b) Three-phase current waveform after complete compensation

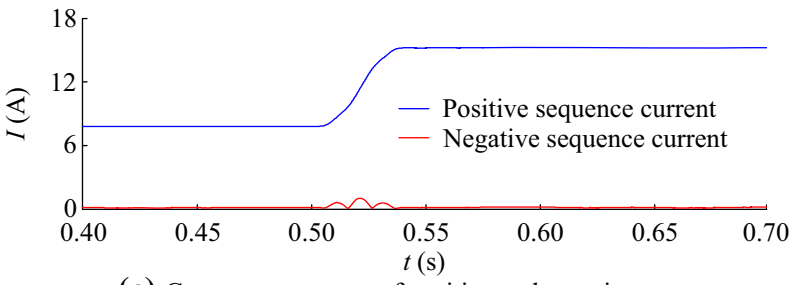

(c) Current component of positive and negative sequence

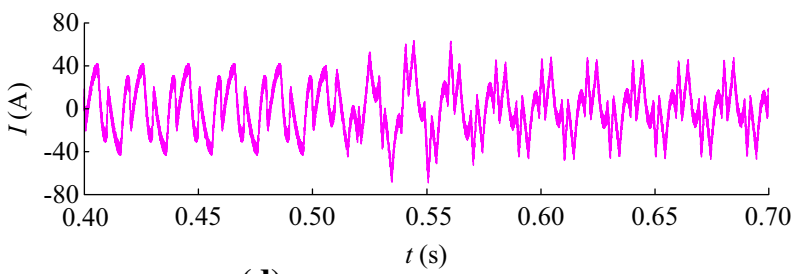

(d) RPC output current of bc side

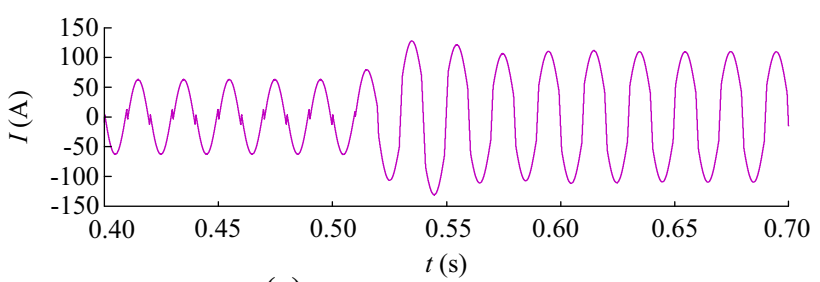

(e) MSVC output current of bc side

Fig. 13 Simulation results under the load power sudden change

In this section, simulation is conducted when there is only load on AC side and the load active power suddenly changes from $20 \mathrm{MW}$ to $40 \mathrm{MW}$ at $t=0.5 \mathrm{~s}$. The simulation results are shown in Fig. 13.

Fig. 13b shows the hybrid compensation system can response within a cycle, which satisfies the requirement of the high-speed electric locomotive load compensation. Fig. 13c shows the positive and negative sequence current of the compensation system after the complete compensation. The negative sequence current has small fluctuations 
Table 5 Parameters of the experiment

\begin{tabular}{ll}
\hline Parameter & Value \\
\hline System voltage & $220 \mathrm{~V}$ \\
Ratio of V/V transformer & $220 / 130 \mathrm{~V}$ \\
Working capacity of RPC & $100 \mathrm{VA}$ \\
Ratio of step-down transformers & $130 / 65 \mathrm{~V}$ \\
Working capacity of MSMCR & $350 \mathrm{var}$ \\
Capacitor & $30 \mu \mathrm{F}$ \\
\hline
\end{tabular}

Table 6 RMS value of three phase current

\begin{tabular}{lllll}
\hline $\begin{array}{l}\text { Three } \\
\text { phase } \\
\text { current }\end{array}$ & $\begin{array}{l}\text { Before } \\
\text { compensation } \\
(\mathrm{A})\end{array}$ & $\begin{array}{l}\text { Complete } \\
\text { compensation } \\
(\mathrm{A})\end{array}$ & $\begin{array}{l}\varepsilon_{U}=1.3 \% \\
(\mathrm{~A})\end{array}$ & $\begin{array}{l}\varepsilon_{U}=2.6 \% \\
(\mathrm{~A})\end{array}$ \\
\hline$I_{\mathrm{A}}$ & 3.24 & 2.34 & 2.35 & 2.44 \\
$I_{\mathrm{B}}$ & 0.03 & 2.30 & 1.86 & 1.42 \\
$I_{\mathrm{C}}$ & 3.21 & 2.41 & 2.86 & 3.09 \\
\hline
\end{tabular}

in a short time when the load suddenly changes, because the MATLAB negative sequence calculation needs a period of 0.02 s. Fig. 13d and Fig. 13e show the RPC and MSVC output current of bc side respectively. It can be seen that MSVC output current increases slowly and tend to be steady and RPC output current first increases then decreases and finally tend to be steady, which well made up for the MSVC slow response speed. Therefore, the overall system can response within a cycle.

Simulation results show that the electromagnetic hybrid compensation theory can effectively compensate the negative sequence current generated by high speed railway, and the complete and optimization compensation control strategy can limit the unbalance current of traction power supply system to the allowed range. System simulation results are consistent with theoretical calculation value, verifying the correctness and effectiveness of the proposed electromagnetic hybrid compensation theory.

\section{Experiment}

\subsection{Introduction of experiment}

In order to validate the proposed EHCS structure and the correctness and effectiveness of its control strategy, an unbalanced compensation experiment platform was established for the high speed railway power system.

Since the high speed railway power factor is close to 1 and almost does not contain low harmonics, $676 \mathrm{~W}$ impedance load is applied to simulate high speed railway electric locomotive load. Two single-phase transformers with the ratio of $220 \mathrm{~V}: 130 \mathrm{~V}$ were used as the V/V traction transformer. The rated capacity of RPC is $100 \mathrm{VA}$, and the RPC uses IPM bridge circuit configuration which is controlled by DSP2812 with hysteresis current PI control. RPC is connected to two power supply arm through two isolation transformers with turn's ration of $130 \mathrm{~V} / 65 \mathrm{~V}$. Three groups of MSVC are composed of three MSMCR with the capacity of 350 var and FC in parallel, which are installed on three-phase output port at the traction transformer secondary side with high-pass filters. The fixed capacitor used in experiment is 30 uf. PLC calculates MSMCRs' sending power according to the measured value and controls the MSMCRs' pulse delay angle. The parameters of the experiment are shown in Table 5.

\subsection{Experiment results}

Experiment results are shown in Table 6. Before compensation, because the loads are concentrated on ac-phase, only A-phase and C-phase have mutually reverse currents in the primary winding of the simulated $\mathrm{V} / \mathrm{V}$ traction transformer and B-phase has only a small amount of transformer no-load current. At this time, the current unbalanced degree is large. After the complete compensation strategy worked, the three phase current waveforms are nearly balanced. Three phase current after the optimization compensation strategy which take $\varepsilon_{U}=1.3 \%$ and $\varepsilon_{U}=2.6 \%$ as constraint conditions worked are shown in Table 6 , respectively. The three phase current unbalance degree can be calculated as $21.1 \%$ and $42.4 \%$, respectively.

The experimental results show that the electromagnetic hybrid compensation system theory described is feasible and effective.

\section{Conclusions}

The paper puts forward a electromagnetic hybrid compensation system (EHCS) for high-speed railway traction supply system to make full use of reliability and economy of MSVC and technicality and flexibility of RPC. By assigning the proportion of RPC active and reactive power, the MSVC compensation in EHCS can be the minimum. Besides, the optimization compensation strategy under the condition of coming up to the relative standard is conducted, which can reduce more MSVC compensation capacity further. Simulation and experiments verified the validity of the EHCS structure and the proposed compensation strategy, which laid a solid foundation for further practical application. 
Acknowledgment This work was supported by National Key Technology Support Program (No.2013BAA02B00), National Natural Science Foundation of China (No.50807041), Asia Pacific Economic Cooperation Fund, Hubei province science and technology support program (No.2014BAA013), the Fundamental Research Funds for the Central Universities (No.2042014kf0233) and the Fundamental Research Funds for the Central Universities (No.2014207020202).

Open Access This article is distributed under the terms of the Creative Commons Attribution 4.0 International License (http:// creativecommons.org/licenses/by/4.0/), which permits unrestricted use, distribution, and reproduction in any medium, provided you give appropriate credit to the original author(s) and the source, provide a link to the Creative Commons license, and indicate if changes were made.

\section{References}

[1] Chang GW, Lin HW, Chen SK (2004) Modeling characteristics of harmonic currents generated by high-speed railway traction drive converters. IEEE Trans Power Deliver 19(2):766-773

[2] Luo A, Peng SJ, Wu CP et al (2012) Power electronic hybrid system for load balancing compensation and frequency-selective harmonic suppression. IEEE Trans Ind Electron 59(2):723-732

[3] Ma FJ, Luo A, Xu XY et al (2013) A simplified power conditioner based on half-bridge converter for high-speed railway system. IEEE Trans Ind Electron 60(2):728-738

[4] Ostroznik S, Bajec P, Zajec P (2010) A study of a hybrid filter. IEEE Trans Ind Electron 57(3):935-942

[5] GB/T 15543-2008. Power quality: Three-phase voltage unbalance (in Chinese)

[6] Orillaza JRC, Wood AR (2013) Harmonic state-space model of a controlled TCR. IEEE Trans Power Deliver 28(1):197-205

[7] Chen XX, Chen BC, Tian CH et al (2012) Modeling and harmonic optimization of a two-stage saturable magnetically controlled reactor for an arc suppression coil. IEEE Trans Ind Electron 59(7):2824-2831

[8] Luo A, Ma FJ, Wu CP et al (2011) A dual-loop control strategy of railway static power regulator under $\mathrm{V} / \mathrm{V}$ electric traction system. IEEE Trans Power Electron 26(7):2079-2091

[9] Luo A, Wu CP, Shen J et al (2011) Railway static power conditioners for high-speed train traction power supply systems using three-phase V/V transformers. IEEE Trans Power Electron 26(10):2844-2856

[10] Lao KW, Wong MC, Dai NY et al (2016) Analysis of DC-link operation voltage of a hybrid railway power quality conditioner and its PQ compensation capability in high-speed cophase traction power supply. IEEE Trans Power Electron 31(2):1643-1656

[11] Lao KW, Wong MC, Dai NY et al (2015) A systematic approach to hybrid railway power conditioner design with harmonic compensation for high-speed railway. IEEE Trans Power Electron 62(2):930-942

[12] Dai NY, Wong MC, Lao KW et al (2014) Modelling and control of a railway power conditioner in co-phase traction power system under partial compensation. IET Power Electron 7(5):1044-1054

[13] Hu SJ, Zhang ZW, Li Y et al (2015) A new railway power flow control system coupled with asymmetric double LC branches. IEEE Trans Power Electron 30(10):5484-5498
[14] Hu SJ, Zhang ZW, Chen YH et al (2015) A new integrated hybrid power quality control system for electric railway. IEEE Trans Ind Electron 62(10):6222-6232

[15] Dai NY, Lao KW, Wong MC et al (2012) Hybrid power quality conditioner for co-phase power supply system in electrified railway. IET Power Electron 5(7):1084-1094

[16] Kim H, Blaabjerg F, Bak-Jensen B (2002) Spectral analysis of instantaneous powers in single-phase and three-phase systems with use of $p-q-r$ theory. IEEE Trans Power Electron 17(5): $711-720$

Jiaxin YUAN received the B.S. and Ph.D. degree from the School of Electrical Engineering, Wuhan University, China, in 2002 and 2007 repectively. He was now an Associate Professor in School of Electrical Engineering, Wuhan University,. His research interests include power electronics system control, power quality issues, and application and control of inverters.

Yongheng ZHONG is pursuing his master degree in School of Electrical Engineering, Wuhan University, China. His research interest includes power quality of railway power supply system.

Chenmeng ZHANG is pursuing his doctor degree in School of Electrical Engineering, Wuhan University, China. His research interest of power quality of railway power supply system.

Wenjun ZENG received her master degree in School of Electrical Engineering, Wuhan University, China. Her research interest includes power quality of railway power supply system.

Baichao CHEN is a Professor of School of Electrical Engineering, Wuhan University, China. His research interests include high-voltage engineering, power quality, and power electronic applications in highvoltage engineering.

Cuihua TIAN is an Associate Professor in School of Electrical Engineering, Wuhan University, China. Her research interests include high-voltage engineering and power quality, and microcomputerbased control system.

Changhong DENG is a Professor in School of Electrical Engineering, Wuhan University, China. Her current research interests include power quality, and new energy generation.

Min ZHOU is an Associate Professor in School of Resource and Environment Science, Wuhan University, China. His research interests include power quality and applications of new materials.

Kazunobu MURAMATSU is a Professor in Department of Advanced Technology Fusion, Saga University, Japan. His current research interests include power quality and electromagnetism calculation.

Jin WANG is currently with the department of Electrical and Computer Engineering in the Ohio State University, US. He has been an Associate Editor for IEEE Transactions on Industry Application since March 2008. His research interests include wide bandgap device based power electronics circuits and control, interface for renewable energy sources, hybrid electrical vehicle/fuel cell vehicle, high power converters and inverters, flexible AC Transmission system devices (FACTS), high voltage DC transmission, and high voltage engineering. 